\title{
Impact of Indonesia's national health insurance scheme on inequality in access to maternal health services: A propensity score matched analysis
}

\author{
Kanya Anindya ${ }^{1}$, John \\ Tayu Lee ${ }^{2}$, Barbara \\ McPake ${ }^{2}$, Siswanto Agus \\ Wilopo $^{3}$, Christopher \\ Millett $^{4}$, Natalie Carvalho ${ }^{5}$ \\ ${ }^{1}$ School of Population and Global \\ Health, The University of Mel- \\ bourne, Melbourne, Victoria, \\ Australia \\ ${ }^{2}$ Nossal Institute for Global Health, \\ School of Population and Global \\ Health, The University of Mel- \\ bourne, Melbourne, Victoria, \\ Australia \\ ${ }^{3}$ Center for Reproductive Health and \\ Department of Biostatistics, Epi- \\ demiology and Population Health, \\ Faculty of Medicine, Public Health \\ and Nursing, Universitas Gadjah \\ Mada, Yogyakarta, Indonesia \\ ${ }^{4}$ Public Health Policy Evaluation \\ Unit, School of Public Health, Im- \\ perial College London, London, UK \\ ${ }^{5}$ Centre for Health Policy \& Global \\ Burden of Disease Group, School \\ of Population and Global Health, \\ The University of Melbourne, Mel- \\ bourne, Victoria, Australia
}

\section{Correspondence to:}

Dr Natalie Carvalho

Centre for Health Policy \& Global

Burden of Disease Group

School of Population and Global

Health

The University of Melbourne

207-221 Bouverie St.

Parkville

Melbourne, Victoria

Australia

natalie.carvalho@unimelb.edu.au
Background Reducing inequality in maternal, neonatal and infant mortality are key targets in the Sustainable Development Goals. This study is the first to evaluate the impact of Indonesia's national health insurance scheme, Jaminan Kesehatan Nasional (JKN), on access to maternal health services by sociodemographic status.

Methods: Using data from the 2017 Indonesia Demographic and Health Survey (IDHS) on women with live births in 2016-2017, we conducted propensity score matching (PSM) analysis to evaluate the association of JKN enrollment on the following maternal health care utilisation outcomes: (1) at least four antenatal care (ANC4+) visits; (2) ANC4+ visits and received essential components of ANC; (3) skilled birth attendance; (4) facility-based delivery; (5) post-natal care (PNC); and (6) PNC with skilled provider. Analyses were conducted at the national level and by economic subgroup and region of residence. Additionally, we investigated the potential negative impact of JKN on access to maternal health services among the uninsured population by looking at trends over time using data from the 2012 and 2017 IDHS.

Results Of the 5429 women who had recently given birth, 61\% were insured by JKN in 2017. After matching treated and untreated women on key sociodemographic characteristics, enrollment in JKN was associated with a higher prevalence of receiving ANC4+ visits (7.4\%, 95\% confidence interval $(\mathrm{CI})=4.8$ 9.39); ANC4+ visits and received essential components of ANC (5.6\%, 95\% $\mathrm{CI}=3.3-7.9)$; skilled birth attendance $(3.0 \%, 95 \% \mathrm{CI}=1.5-4.5$; facility-based delivery (10.2\%, 95\% CI=7.5-12.7); PNC (4.0\%, 95\% CI=2.2-5.7); PNC with skilled provider $(4.5 \%, 95 \% \mathrm{CI}=2.6-6.5)$. Effect sizes were larger among the poor and those living in less-developed areas, such as Eastern Indonesia and Sulawesi, except for at least ANC4+ and received clinical components.

Conclusions Expansion of health insurance coverage was associated with reductions in sociodemographic inequalities in access to maternal health services in Indonesia. However, large differences in utilisation persist across regions and by economic subgroup. Accelerating progress toward universal health coverage may reduce health inequalities in other low and middle-income countries.

Despite declines in maternal, newborn, and child mortality since implementation of the Millennium Development Goals in 1990, these burdens remain disproportionately high among disadvantaged groups in low- and middle-income countries (LMICs) [1,2]. Achieving equitable access to high quality essential maternal health service has been identified as an important instrument for countries to reduce ma- 
ternal and neonatal mortality and attain Sustainable Development Goals (SDGs) 3.1 and 3.2 [3]. Indonesia, a lower-middle income country, has one of the highest maternal mortality ratios (MMRs) in the South-East Asia Region [4] at 305 maternal deaths per 100000 live births, with a substantially higher MMR of 489 in Eastern Indonesia [3,5,6]. Aside from the direct loss of life, a maternal death can result in profound negative health consequences for neonates and other children in the household, can lead to household economic deprivation, and productivity losses to society $[7,8]$.

A high burden of maternal death is often linked to inequality in access to maternal health services [8-10]. Women from disadvantaged groups, including the poor and those living in rural and remote areas, often face increased financial barriers and limited access to high quality health services, resulting in lower coverage of essential maternal health care services [8-15]. These inequities also persist across regions. For example, health services are more concentrated in the more developed islands of Java-Bali, while lack of services and understaffing remains a problem in less developed regions of Sulawesi and Eastern Indonesia $[14,16]$.

In 2014, the Indonesian government rolled out the world's largest single-payer health insurance programme [12], Jaminan Kesehatan Nasional (JKN), or National Health Insurance, to achieve universal health coverage (UHC) by 2019. The programme integrates and replaces all previous fragmented social health insurance schemes, including Jamkesmas, Jamkesda and Askeskin $[12,17]$. Not only covering the poor and near-poor, JKN scheme is compulsory for all people in Indonesia, with a differentiated timeline until it covers the entire population. Participants are categorized into four groups: 1) subsidised participants or Penerima Bantuan Iuran (PBI)/Premium assistance beneficiaries, for the poor and near-poor; 2) salary earners and formal workers, for employees in the public and private sectors; 3 ) informal workers, for the non-poor who work in the informal sector; and 4) non-salaried workers [12]. Data from Social Security Agency for Health show the incline of enrolment rates from 48\% in January 2014 to 85\%, or almost 225 million people by the end of 2019 with around 60\% among those classified as subsidised participants or poor and near-poor $[18,19]$. The programme provides comprehensive coverage of treatment for most outpatient and inpatient visits in public and enlisted private facilities. For maternal health services, JKN covers antenatal, delivery, and postnatal care, as well as referral services at secondary and tertiary hospitals [20]. Despite the introduction of JKN, the burden of out-of-pocket expenditure on health stood at $40 \%$ in 2018 [21], with the insured still incurring high OOPE.

Evidence on the impact of JKN on coverage of maternal health services and inequalities in service utilisation is lacking. Prior studies from Indonesia on maternal health and JKN were descriptive, based on older data, and focused on district-level populations [20,22-24]. No studies have used nationally-representative data to examine the impact of JKN across economic subgroups and regions [22,24]. A study using 2016 data found that JKN accelerates poor women's access to skilled birth attendance [20]. However, this study did not consider other maternal health care utilisation outcomes and did not assess the difference in impact across all economic subgroups and regions. We present the first study that uses recent population-level, nationally-representative data from 2017 to examine the impact of JKN on inequalities in maternal health services use across the continuum of care, from antenatal to intrapartum, to postpartum care. We further investigate how the impact of JKN on access to maternal health services varies across economic subgroups and regions of the country.

\section{METHODS}

The Strengthening and Reporting of Observational Studies in Epidemiology (STROBE Statement) was used as a guidance in reporting this study [25].

\section{Data set and sample}

We used cross-sectional data from the 2012 and 2017 Indonesia Demographic and Health Survey (IDHS), carried out by Statistics Indonesia (Badan Pusat Statistik) in collaboration with the National Population and Family Planning Board (Badan Kependudukan dan Keluarga Berencana Nasional) and the Ministry of Health [26]. DHS applies standardised instruments to measure key maternal service utilisation to ensure validity and comparability of results across countries. In Indonesia, the survey used a multi-stage stratified design to generate a representative sample from all 34 provinces. The 2017 IDHS was used for the main analysis, with the 2012 IDHS used to explore the time trend of service use between 2012 and 2017. There were 45607 and 49627 women aged 15-49 who completed the interview in 2012 IDHS and 2017 IDHS, respectively. The response rates were 95.9\% (2012) and 97.8\% (2017). A detailed description of the survey objectives and methods can be found elsewhere [26,27]. 
For the main analysis, our sample included women aged 15-49 years who had a recent live birth in 20162017. IDHS only recorded a complete information of maternal health services utilization for most recent live birth. For those with multiple births, only the last of multiple births are considered. Hence, each respondent was included only once in the analysis. To ensure differences in outcomes can be attributed to JKN, we removed 117 respondents ( $2 \%$ of the sample) who were only covered by other insurance including private insurance and employer-provided insurance plans. After removing respondents who had missing values in outcome and independent variables ( $0.6 \%$ of the sample), our sample consisted of 5717 respondents or 5429 respondents after weighting (sample flowchart in Figure S1 in the Online Supplementary Document). Sampling weight was applied to account for the multiple-stage design of DHS data set.

\section{Variables}

\section{Outcomes variables}

We examined six indicators of maternal health service use: 1) at least 4 antenatal care (ANC 4+) visits; 2) ANC4+ visits and received clinical components of ANC; 3) skilled birth attendance (SBA); 4) facility-based delivery; 5) post-natal care (PNC); and 6) and PNC with a skilled health provider. All measures were coded as 0 for "no" or 1 for "yes". The definition of ANC visits refers to the WHO Focused ANC (FANC) and the Ministry of Health Decree No.97/2014, which includes the first visit in the first trimester, second visit at second trimester, and the third and fourth visits at third trimester [28]. We further assessed the clinical intervention received by respondents: including weight and height measurement, blood pressure measurement, urine and blood sample taken, stomach examined, consultation, and iron supplementation. Women who had ANC4+ and received the eight essential clinical components of routine ANC from skilled providers were categorised receiving good quality of ANC services. Skilled birth attendance was defined as delivery attended by doctor, nurse, midwife, and village/auxiliary midwife [29]. Facility-based delivery was defined as delivery at a hospital, health centre, maternity home, and clinic. PNC was defined as receiving care within 2 days after delivery (detailed definitions in Table S1 in the Online Supplementary Document) [26].

\section{Treatment and control groups}

The primary independent variable is the respondent's enrolment in JKN, using the questions: "Are you covered by any health insurance?" and "What type of health insurance are you covered by?" to categorise the following:

a) Treatment group $(\mathrm{N}=3,661)$ : respondents who answered affirmatively for having JKN coverage (either PBI/Jamkesda (regional health insurance) or Non-PBI).

b) Control group $(\mathrm{N}=2,044)$ : respondents who had no health insurance at the time of the survey.

\section{Covariates}

We controlled for maternal age at the time of the survey, marital status, birth order, level of education, women's employment status, wealth index (as constructed by the DHS based on household assets, housing materials, water access and sanitation facilities), media exposure (internet and newspaper), residency and region of residence [26]. Wealth index and region of residence were used to measure inequalities in access to maternal health services. Existing studies were used in selecting covariates to minimise selection bias of JKN enrolment $[16,23,24,30]$.

\section{Statistical analysis}

Propensity scoring matching (PSM) approach was applied to compare maternal health services utilisation among those insured and not insured with JKN. This statistical method was selected as women's enrolment in health insurance is not random and can be strongly influenced by unobservable and observable characteristics (selection bias) [23,24]. In brief, the analysis consists of three stages.

First, we applied a logit model (due to the dichotomous outcome indicator) to estimate the propensity score, or a predicted probability of insurance by JKN given a set of observable covariates. Second, we used the psmatch 2 command to match participants and non-participants on the basis of the propensity score. To ensure that the propensity score's distribution was similar for insured (treatment) and uninsured (control) women, we evaluate the quality of matched pairs by applying balance diagnostic test. Following the 
Rosenbaum and Rubin, we used absolute standardised mean difference as the most common measure to ensure balance within treatment and control group with respect to the covariates [31-33]. Studies indicates that standardised mean differences less than $10 \%$ is considered balance $[31,34]$. We also computed other metrics, pseudo- $R^{2}$, Rubin's $B$ and Rubin's $R$, as additional measures to ensure our quality of matching. The Rubin's $B$ should be less than 25 and $R$ ranged from 0.5 to 2 . The balance check was performed for different matching algorithms, including nearest neighbour (NN) with and without replacement, radius matching, and Kernel matching. We selected Kernel matching for our main analysis as the result shows the satisfactory balance in all diagnostics checks (balancing check in Table S2-S4 in the Online Supplementary Document). Lastly, we use the kmatch command [35] to estimate the difference in maternal health services utilisation between the treated and control with a calliper of bandwidth equal to 0.2 of the standard deviation of the logit of the propensity score. To improve accuracy, bootstrapping with 200 replications was performed to estimate the standard error. Stratified analyses were conducted to assess the impact of JKN across population groups. All statistical analyses were conducted using Stata 14.2 SE (StataCorp, College Station, Texas 77845, USA).

\section{Robustness check}

We performed a sensitivity analysis using Coarsened Exact Matching (CEM) algorithm. CEM matched the treatment group to the control group with the exact same covariates value, which mostly produces very few matches and may also narrow the representativeness of the remaining sample [36]. We also conducted a sensitivity analysis using the Mantel and Haenszel (MH) method. The Gamma coefficient $(\Gamma)=1$ indicates there is no hidden bias, while higher values of $\Gamma$ indicates more influence of unobserved factors. This study set the $\Gamma$ between 1 and 2 with an increment of 0.1 , an approach adopted by previous studies using PSM $[23,37]$. Furthermore, we applied the multiple hypothesis testing using Bonferroni and Holm procedure to control Type 1 error (the probability of rejecting a true null hypothesis) inflation due to simultaneous testing of null hypotheses for the six outcomes [38,39].

Any public health insurance programme, financing strategies or otherwise, can have unintended consequences. We investigated the potential negative impact of JKN on access to maternal health services for the uninsured population comparing their health care service utilisation rates before and after the implementation of JKN, using data from 2012 to 2017.

\section{RESULTS}

\section{Sample characteristics}

The characteristics of our study sample are reported in Table 1. Overall, 61\% of the women who recently gave birth were insured by JKN in 2017. The majority of respondents were less than 35 years old, married, with two or fewer children, had completed secondary education, had no occupation, were not exposed to internet and newspaper, and lived in Java-Bali region. Despite the poor and near-poor being eligible for full or partial subsidies through JKN, there was little difference in the distribution of respondents across wealth quintiles within the insured and uninsured population, with the exception being fewer respondents within the highest wealth quintile among the uninsured group. The proportion of women receiving maternal health services was higher for those insured with JKN compared with the uninsured: (1) ANC4+ visits (78.6\% vs 71.0\%); (2) ANC 4+ visits and received clinical components of ANC $(23.4 \%$ vs $19.8 \%$ ); (3) SBA (94.4\% vs $90.6 \%$ ); (4) facility-based delivery ( $86.8 \%$ vs $78.1 \%$ ); (5) PNC $(90.2 \%$ vs $85.4 \%$ ); (6) PNC with skilled providers (89.3\% vs $83.7 \%$ ). Sample characteristics for 2012 IDHS are available in Table S3 in the Online Supplementary Document.

\section{Propensity score estimation and balance diagnostics test}

Table 2 presents the predicted probability of enrolment in JKN according to logistic regression model. Type of employment, exposure to internet, and residency were the most important predictors of women's enrolment status in JKN. For example, women who work in white-collar jobs were 2.34 times (95\% CI=1.74-3.16) more likely to be insured by JKN compared to women who had no occupation. Women who were exposed to internet at least once a week had 1.46 (95\% CI=1.09-1.97) higher probability of being insured in JKN than women who did not expose to internet. Those who lived in urban area had 1.36 (95\% CI=1.15-1.62) higher odds of being insured by JKN compared to rural groups. No significant differences in enrolment status were found for the other wealth quintiles, as compared to the poorest group (Table 2). 
Table 1. Background characteristics of women who had recent live birth between 2016 and $2017^{*}$

\begin{tabular}{|c|c|c|c|c|c|c|}
\hline \multirow{2}{*}{ Variabies } & \multicolumn{2}{|c|}{ Aul } & \multicolumn{2}{|c|}{ TREATMENT: IWSURED BY JKW } & \multicolumn{2}{|c|}{ CONTROL: UNINSURED BY JKWI } \\
\hline & $\%$ & N & $\%$ & N & $\%$ & N \\
\hline Overall $\dagger$ & 100.0 & 5429 & 61.4 & 3332 & 38.3 & 2097 \\
\hline \multicolumn{7}{|l|}{ Outcomes variables: } \\
\hline (a) ANC 4+ & 75.6 & 4107 & 78.6 & 2618 & 71.0 & 1489 \\
\hline $\begin{array}{l}\text { (b) ANC } 4+\text { and received clinical components of } \\
\text { ANC }\end{array}$ & 22.0 & 1194 & 23.4 & 780 & 19.8 & 414 \\
\hline (c) Skilled birth attendance & 92.9 & 5045 & 94.4 & 2892 & 90.6 & 1900 \\
\hline (d) Facility-based delivery & 83.5 & 4531 & 86.8 & 3145 & 78.1 & 1639 \\
\hline (e) PNC & 88.4 & 4795 & 90.2 & 3004 & 85.4 & 1791 \\
\hline (f) PNC with skilled provider & 87.1 & 4729 & 89.3 & 2097 & 83.7 & 1756 \\
\hline \multicolumn{7}{|l|}{ Control variables: } \\
\hline \multicolumn{7}{|l|}{ Age (in years): } \\
\hline $15-24$ & 25.1 & 1364 & 22.9 & 764 & 28.6 & 600 \\
\hline $25-34$ & 51.9 & 2819 & 52.4 & 1745 & 51.2 & 1074 \\
\hline $35-42$ & 21.0 & 1140 & 22.4 & 747 & 18.7 & 392 \\
\hline $42-49$ & 2.0 & 107 & 2.3 & 76 & 1.5 & 31 \\
\hline \multicolumn{7}{|l|}{ Marital status: } \\
\hline Unmarried & 1.9 & 104 & 1.6 & 54 & 2.4 & 50 \\
\hline Married & 98.1 & 5325 & 98.4 & 3277 & 97.6 & 2047 \\
\hline \multicolumn{7}{|l|}{ Birth order: } \\
\hline 1 & 32.7 & 1776 & 32.4 & 1081 & 33.2 & 695 \\
\hline 2 & 35.3 & 1918 & 34.2 & 1139 & 37.1 & 778 \\
\hline 3 & 18.9 & 1027 & 19.5 & 648 & 18.1 & 379 \\
\hline 4 & 8.0 & 437 & 8.4 & 279 & 7.5 & 158 \\
\hline 5 or more & 5.0 & 271 & 5.5 & 184 & 4.2 & 87 \\
\hline \multicolumn{7}{|l|}{ Education: } \\
\hline None/incomplete primary & 6.5 & 352 & 6.4 & 212 & 6.7 & 140 \\
\hline Complete primary & 18.0 & 979 & 16.9 & 562 & 19.9 & 417 \\
\hline Incomplete secondary & 28.3 & 1535 & 25.6 & 852 & 32.6 & 683 \\
\hline Complete secondary & 31.0 & 1684 & 30.9 & 1029 & 31.2 & 655 \\
\hline Higher/vocational & 16.2 & 879 & 20.3 & 677 & 9.6 & 202 \\
\hline \multicolumn{7}{|l|}{ Employment: } \\
\hline None & 56.7 & 3076 & 52.7 & 1755 & 63 & 1320 \\
\hline Agriculture & 6.8 & 367 & 6.2 & 206 & 7.6 & 160 \\
\hline Blue-collar & 24.9 & 1352 & 25.5 & 849 & 24 & 503 \\
\hline White-collar & 11.7 & 634 & 15.6 & 520 & 5.4 & 114 \\
\hline \multicolumn{7}{|l|}{ Exposure to internet: } \\
\hline Not at all & 61.7 & 3351 & 57.5 & 1916 & 68.4 & 1435 \\
\hline Less than once a week & 30.3 & 1645 & 32.7 & 1090 & 26.5 & 556 \\
\hline At least once a week & 8.0 & 433 & 9.8 & 326 & 5.1 & 107 \\
\hline \multicolumn{7}{|l|}{ Exposure to newspaper: } \\
\hline Not at all & 4.1 & 220 & 3.8 & 128 & 4.4 & 92 \\
\hline Less than once a week & 12.9 & 702 & 13.3 & 443 & 12.3 & 259 \\
\hline At least once a week & 83.0 & 4506 & 82.9 & 2760 & 83.3 & 1746 \\
\hline \multicolumn{7}{|l|}{ Wealth index: } \\
\hline Very poor & 20.2 & 1098 & 19.5 & 650 & 21.4 & 448 \\
\hline Poor & 20.9 & 1135 & 19.2 & 640 & 23.6 & 495 \\
\hline Middle & 19.9 & 1079 & 19.2 & 640 & 20.9 & 439 \\
\hline Rich & 20.8 & 1129 & 20.6 & 688 & 21.1 & 442 \\
\hline Very rich & 18.2 & 987 & 21.4 & 714 & 13.0 & 273 \\
\hline \multicolumn{7}{|l|}{ Residency: } \\
\hline Rural & 51.9 & 2818 & 48.3 & 1610 & 57.6 & 1208 \\
\hline Urban & 48.1 & 2611 & 51.7 & 1721 & 42.4 & 890 \\
\hline \multicolumn{7}{|l|}{ Region of residency: } \\
\hline Eastern Indonesia & 3.5 & 192 & 3.9 & 131 & 2.9 & 62 \\
\hline Sulawesi & 7.4 & 402 & 8.9 & 297 & 5 & 105 \\
\hline Kalimantan & 6.0 & 326 & 5.2 & 174 & 7.2 & 152 \\
\hline Nusa Tenggara & 4.9 & 263 & 4.5 & 151 & 5.4 & 113 \\
\hline Sumatra & 22.7 & 1235 & 22.9 & 765 & 22.4 & 470 \\
\hline Java \& Bali & 55.4 & 3010 & 54.4 & 1814 & 57 & 1196 \\
\hline
\end{tabular}

PNC - post-natal care, JKN - Jaminan Kesehatan Nasional

*This table includes all women who had birth recent live birth between 2016-2017 before matching. ANC 4+: At least 4 antenatal care visits. Percentages and Ns are weighted. Unweighted sample size $=5717$. 
Table 2. Factor associated with Jaminan Kesehatan Nasional (JKN) enrolment in 2017*

\begin{tabular}{|c|c|c|c|}
\hline VARIABIES & AOR & (95\% CI) & $P_{\text {-value }}$ \\
\hline \multicolumn{4}{|l|}{ Age: } \\
\hline $15-24 y$ & Ref. & & \\
\hline $25-34 y$ & 1.12 & $(0.92-1.37)$ & 0.248 \\
\hline $35-42 y$ & 1.31 & $(1.00-1.73)$ & 0.054 \\
\hline $42-49 y$ & 1.76 & $(0.95-3.26)$ & 0.073 \\
\hline \multicolumn{4}{|l|}{ Marital status: } \\
\hline Unmarried & Ref. & & \\
\hline Married & 1.37 & $(0.86-2.18)$ & 0.187 \\
\hline \multicolumn{4}{|l|}{ Birth order: } \\
\hline 1 & Ref. & & \\
\hline 2 & 0.96 & $(0.79-1.17)$ & 0.695 \\
\hline 3 & 1.06 & $(0.83-1.36)$ & 0.655 \\
\hline 4 & 1.02 & $(0.74-1.39)$ & 0.915 \\
\hline 5 or more & 1.25 & $(0.83-1.87)$ & 0.284 \\
\hline \multicolumn{4}{|l|}{ Education: } \\
\hline None/incomplete primary & Ref. & & \\
\hline Complete primary & 0.94 & $(0.70-1.27)$ & 0.684 \\
\hline Incomplete secondary & 0.89 & $(0.66-1.20)$ & 0.461 \\
\hline Complete secondary & 0.97 & $(0.71-1.33)$ & 0.855 \\
\hline Higher/vocational & 1.25 & $(0.86-1.80)$ & 0.238 \\
\hline \multicolumn{4}{|l|}{ Employment: } \\
\hline None & Ref. & & \\
\hline Agriculture & 0.96 & $(0.74-1.27)$ & 0.794 \\
\hline Blue-collar & 1.17 & $(0.99-1.40)$ & 0.073 \\
\hline White-collar & 2.34 & $(1.74-3.16)$ & $<0.0001$ \\
\hline \multicolumn{4}{|l|}{ Exposure to internet: } \\
\hline Not at all & Ref. & & \\
\hline Less than once a week & 1.26 & $(1.07-1.47)$ & 0.004 \\
\hline At least once a week & 1.46 & $(1.09-1.97)$ & 0.012 \\
\hline \multicolumn{4}{|l|}{ Exposure to newspaper: } \\
\hline Not at all & Ref. & & \\
\hline Less than once a week & 1.10 & $(0.76-1.58)$ & 0.615 \\
\hline At least once a week & 1.05 & $(0.75-1.48)$ & 0.781 \\
\hline \multicolumn{4}{|l|}{ Wealth index: } \\
\hline Very poor & Ref. & & \\
\hline Poor & 0.85 & $(0.67-1.08)$ & 0.173 \\
\hline Middle & 0.89 & $(0.68-1.15)$ & 0.365 \\
\hline Rich & 0.82 & $(0.62-1.08)$ & 0.150 \\
\hline Very rich & 1.04 & $(0.75-1.44)$ & 0.812 \\
\hline \multicolumn{4}{|l|}{ Residency: } \\
\hline Rural & Ref. & & \\
\hline Urban & 1.36 & $(1.15-1.62)$ & $<0.0001$ \\
\hline \multicolumn{4}{|l|}{ Region of residency: } \\
\hline Eastern Indonesia & Ref. & & \\
\hline Sulawesi & 1.28 & $(0.92-1.80)$ & 0.148 \\
\hline Kalimantan & 0.55 & $(0.38-0.78)$ & 0.001 \\
\hline Nusa Tenggara & 0.63 & $(0.44-0.90)$ & 0.011 \\
\hline Sumatra & 0.73 & $(0.53-1.01)$ & 0.059 \\
\hline Java \& Bali & 0.68 & $(0.49-0.94)$ & 0.021 \\
\hline
\end{tabular}

According to the balance diagnostic checks, we verified that Kernel matching resulted satisfactory balance for all model parameters (in Table S2-S3 in the Online Supplementary Document). After matching, the treatment and control group became comparable, as shown by low standardised difference in means across all covariates ( $<10 \%)$. We also estimated the low pseudo-R2, with Rubin's B and Rubin's R were 7.4 and 0.92 , respectively. The distribution of the propensity score, including region of common support, by control and treatment groups is presented in Figure S2 in the Online Supplementary Document. A total of 12 treated participants were off support after matching and were removed from the sample. The result of the balancing test for the other matching algorithms is available in Table S4 in the Online Supplementary Document.

\section{Effects of JKN on maternal health outcomes}

Table 3 shows the difference in maternal health services utilisation between the insured and uninsured at the national level, as measured by the average treatment effect on the treated (ATT). Enrollment in JKN was associated with an improvement in receiving all six maternal health services $(P<0.0001)$. The highest effect size was found for facility-based delivery, while the smallest effect was for SBA. Enrollment in JKN was associated with greater prevalence in ANC 4+ visits by $7.4 \%$ (95\% CI =4.8-9.9), ANC 4+ visits and received clinical components of routine ANC by $5.6 \%(95 \% \mathrm{CI}=3.3-7.9)$, skilled birth attendance by 3.0\% (95\% CI = 1.5-4.5), facility-based delivery by 10.2 (95\% CI=7.5-12.7), PNC by $4 \%(95 \%$ $\mathrm{CI}=2.2-5.7)$, and $\mathrm{PNC}$ with skilled provider by $4.5 \%$ (95\% $\mathrm{CI}=2.6-6.5)$. Table 3 also shows the percentage change in outcome variables relative to the control group.

\section{Differential effect of JKN by sociodemographic groups}

\section{Economic groups}

Our results by economic subgroup (Figure 1) indicate that the differences in outcomes associated with JKN enrollment were larger for the poorest wealth quintiles compared to the most affluent, although the 95\% confidence intervals overlapped in all but the skilled birth attendance outcome $(\mathrm{ATT}=7.2,95 \% \mathrm{CI}=2.2-12.1$ vs $\mathrm{ATT}=-0.795 \% \mathrm{CI}=-1.3$ to -0.1). However, the effect of JKN enrollment on the quality of routine ANC visits was more pronounced in the rich wealth quantiles. Substantial gaps in maternal health services utilization between the poorest and richest wealth quintiles still exist. For instance, facility-based delivery was 38 percentage points lower for the poorest quintile (58.5\%) compared to the richest (96.9\%) among those insured by JKN.

\section{Regional areas}

Figure 2 shows the difference in maternal health services utilisation between the insured and uninsured across regional areas. Our results indicate that JKN was associated with greater utilisation in Eastern Indonesia compared to Java \& Bali for three outcomes: (1) facility-based delivery (ATT =20, 95\% CI = 10.429.7 vs $A T T=4.0,95 \% \mathrm{CI}=1.2-6.8)$, $\mathrm{PNC}(\mathrm{ATT}=14.1,95 \% \mathrm{CI}=4.0-24.2$ vs $\mathrm{ATT}=2.8,95 \% \mathrm{CI}=0.3-6.0)$, 
and PNC with skilled providers (ATT $=15.1,95 \% \mathrm{CI}=5.8-24.3$ vs ATT $=3.5,95 \% \mathrm{CI}=0.7-6.3$ ). Large and statistically significant differences in ATT were also found for Sulawesi and Kalimantan, for some of utilisation outcomes. However, the findings indicate that inequalities still persist across regional areas. Utilisation of all maternal health services in Eastern Indonesia was much lower than in Sumatra and Java $\&$ Bali. For instance, among those insured by JKN, the percentage of ANC4+ visits in Eastern Indonesia (52.4\%) was 34.3 percentage points lower than in Java \& Bali (86.7\%).

Table 3. The average treatment effect on treated (ATT) of Jaminan Kesehatan Nasional (JKN) on maternal health services*

\begin{tabular}{|c|c|c|c|c|c|c|c|}
\hline Variables & & $\begin{array}{l}\text { TreatMENt Group: } \\
\text { IMSURED BY JKN }\end{array}$ & $\begin{array}{l}\text { Control group: } \\
\text { Uninsured by JKN }\end{array}$ & & ATTt & Percentage changes & SE \\
\hline & & $\%$ & $\%$ & $\%$ & $(95 \% \mathrm{CI}) \dagger$ & $\%$ & \\
\hline \multirow[t]{2}{*}{ (a) \% At least 4 ANC visits } & Unmatched & 73.0 & 65.2 & 7.8 & & & 1.2 \\
\hline & Matched & 73.1 & 65.7 & 7.4 & $(4.8-9.9)^{* * *}$ & $8.8 \%$ & 1.5 \\
\hline \multirow{2}{*}{$\begin{array}{l}\text { (b) \% At least } 4 \text { ANC visits and received } \\
\text { clinical components of ANC }\end{array}$} & Unmatched & 21.0 & 16.3 & 4.7 & & & 1.1 \\
\hline & Matched & 21.0 & 15.4 & 5.6 & $(3.3-7.9)^{* * *}$ & $36.4 \%$ & 1.2 \\
\hline \multirow[t]{2}{*}{ (c) \% Skilled birth attendance } & Unmatched & 92.7 & 88.0 & 4.7 & & & 0.8 \\
\hline & Matched & 92.7 & 89.7 & 3.0 & $(1.5-4.5) * * *$ & $3.3 \%$ & 0.9 \\
\hline \multirow[t]{2}{*}{ (d) \% Facility-based delivery } & Unmatched & 82.2 & 70.0 & 12.2 & & & 1.1 \\
\hline & Matched & 82.2 & 72.0 & 10.2 & $(7.5-12.7) * * *$ & $14.2 \%$ & 1.4 \\
\hline \multirow[t]{2}{*}{ (e) \% PNC } & Unmatched & 88.4 & 81.9 & 6.4 & & & 09 \\
\hline & Matched & 88.4 & 84.4 & 4.0 & $(2.2-5.7)^{* * *}$ & $4.7 \%$ & 1.1 \\
\hline \multirow[t]{2}{*}{ (f) $\%$ PNC with skilled providers } & Unmatched & 87.1 & 79.8 & 7.3 & & & 0.8 \\
\hline & Matched & 87.1 & 82.5 & 4.5 & $(2.6-6.5) * * *$ & $5.5 \%$ & 1.0 \\
\hline
\end{tabular}

ANC - antenatal care, PNC - post-natal care, SE - standard error, ATT - treatment effect on the treated, CI - confidence interval

$* \mathrm{~N}$ after matching $=5705$

$\dagger$ The average treatment effect on the treated (ATT) was calculated using psmatch2 command to estimate the difference of maternal care utilisation between treatment and control. We used Kernel matching with a calliper of bandwidth equal to 0.2 of the standard deviation of the logit of propensity score. To improve accuracy, bootstrapping with 200 times replications was performed to estimate the standard error.

¥Significance: $* P<0.05 ; * * P<0.01 ; * * * P<0.001$

\begin{tabular}{|c|c|c|c|c|c|c|}
\hline \multirow{2}{*}{$\begin{array}{l}\text { Subgroups } \\
\text { At least } 4 \text { ANC }\end{array}$} & Treatment & \multirow[t]{2}{*}{ Control } & \multicolumn{3}{|c|}{$\%$ ATT $(95 \%$ CI) } & \multirow{2}{*}{$P$-value } \\
\hline & & & & & & \\
\hline Very poor & 56.2 & 48.2 & & $\bullet$ & $10.0(4.4-15.6)$ & $<0.0001$ \\
\hline Poor & 70.2 & 61.6 & & $\bullet$ & $8.7(2.2-15.1)$ & 0.009 \\
\hline Middle & 78.4 & 71 & & $\bullet$ & $7.4(1.4-13.4)$ & 0.072 \\
\hline Rich & 80.6 & 78.1 & - & & $2.4(-3.8-8.8)$ & 0.426 \\
\hline Richest & 86.9 & 83.2 & - & $\bullet$ & $3.7(-3.8-11.3)$ & 0.508 \\
\hline \multirow{2}{*}{\multicolumn{4}{|c|}{ At least 4 ANC visits and received clinical components }} & & & \\
\hline Very poor & 10.3 & & & $\bullet$ & $2.7(0.0-5.4)$ & 0.059 \\
\hline Poor & 18.8 & 13.3 & & $\rightarrow$ & $5.5(0.8-10.1)$ & 0.02 \\
\hline Middle & 20.8 & 17.6 & & $\bullet$ & $3.2(-2.5-8.9)$ & 0.268 \\
\hline Rich & 32.0 & 20.6 & & & $-11.4(4.8-17.9)$ & 0.001 \\
\hline Richest & 28.0 & 19.8 & & $\bullet$ & $-\quad 8.2(-0.1-16.5)$ & 0.052 \\
\hline \multicolumn{7}{|c|}{ Skilled birth attendance } \\
\hline Very poor & 78.8 & 71.6 & & - & $7.2(2.2-12.1)$ & 0.005 \\
\hline Poor & 94.0 & 89.8 & & $\rightarrow-$ & $4.2(0.7-7.5)$ & 0.017 \\
\hline Middle & 98.0 & 95.8 & & & $2.2(-0.8-5.2)$ & 0.156 \\
\hline Rich & 99.1 & 96 & & & $3.1(0.0-6.1)$ & 0.051 \\
\hline Richest & 99.3 & 100 & & & $-0.7(-1.3-(-0.1))$ & 0.021 \\
\hline \multicolumn{7}{|c|}{ Facility-based delivery } \\
\hline Very poor & 58.5 & 45.2 & & 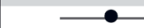 & $-13.3(7.7-18.9)$ & $<0.0001$ \\
\hline Poor & 82.2 & 69.7 & & - & $12.5(7.1-17.9)$ & $<0.0001$ \\
\hline Middle & 90.0 & 81 & & 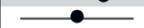 & $9.0(2.4-15.5)$ & 0.007 \\
\hline Rich & 93.2 & 80.6 & & & $12.6(7.3-18.0)$ & $<0.0001$ \\
\hline Richest & 96.9 & 91.9 & & - & $5.0(-1.0-11.1)$ & 0.1 \\
\hline \multicolumn{7}{|l|}{ PNC } \\
\hline Very poor & 76.8 & 67.9 & & 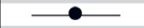 & $8.9(3.7-14.0)$ & $<0.0001$ \\
\hline Poor & 88.2 & 82.6 & & - & $5.6(0.7-10.4)$ & 0.024 \\
\hline Middle & 91.6 & 89.5 & - & $\bullet$ & $-0.2(-2.9-7.1)$ & 0.876 \\
\hline Rich & 94.9 & 88.6 & & $\longrightarrow$ & $6.3(1.5-11.0)$ & 0.01 \\
\hline Richest & 95.2 & 94.7 & — & & $-0.5(-3.6-4.6)$ & 0.812 \\
\hline \multicolumn{7}{|c|}{ PNC with skilled provider } \\
\hline Very poor & 73.3 & 63 & & - & $10.3(4.5-15.9)$ & $<0.0001$ \\
\hline Poor & 86.9 & 80.7 & & 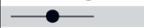 & $6.2(1.3-11.0)$ & 0.013 \\
\hline Middle & 91 & 88.2 & & & $2.8(-1.6-7.2)$ & 0.206 \\
\hline Rich & 95.9 & $87.8-$ & & & $8.1(2.4-11.7)$ & 0.003 \\
\hline \multirow[t]{2}{*}{ Richest } & 95.2 & 94.7 & & - & $0.5(-3.6-4.6)$ & 0.808 \\
\hline & & -8 & -3 & 121 & 17 & \\
\hline
\end{tabular}

Figure 1. The average treatment effect on treated (ATT) of Jaminan Kesehatan Nasional (JKN) on maternal health services, by economic status. ANC - antenatal care, PNC - post-natal care.

\begin{tabular}{|c|c|c|c|c|c|}
\hline Subgroups & Treatment & Control & $\%$ ATT $(95 \%$ & CI) & $P$-value \\
\hline \multicolumn{6}{|l|}{ At least $4 \mathrm{ANC}$ visits } \\
\hline Eastem Indonesia & 52.4 & 41.9 & $\longrightarrow$ & $10.6(0.9-20.2)$ & 0.032 \\
\hline Sulawesi & 62.5 & 53.4 & $\bullet$ & $9.1(0.1-18.2)$ & 0.049 \\
\hline Kalimantan & 76.1 & 65.3 & $\bullet$ & $10.7(0.0-21.6)$ & 0.050 \\
\hline Nusa Tenggara & 70.9 & 69.7 & 5 & $1.3(-0.8-10.9)$ & 0.795 \\
\hline Sumatra & 73.7 & 66.7 & $\bullet$ & $6.5(-0.5-13.5)$ & 0.078 \\
\hline Java \& Bali & 86.7 & 80.8 & $\rightarrow$ & $5.9(2.3-9.5)$ & 0.015 \\
\hline \multicolumn{6}{|c|}{ At least 4 ANC visits and received clinical components } \\
\hline Eastem Indonesia & 11.1 & 5.6 & - & $5.5(0.01-10.9)$ & 0.047 \\
\hline Sulawesi & 17.2 & 6.9 & $\longrightarrow$ & $10.3(5.1-15.5)$ & $<0.0001$ \\
\hline Kalimantan & 29.4 & 19.3 & $\bullet$ & $10.1(0.3-19.8)$ & 0.042 \\
\hline Nusa Tenggara & 23.8 & $26.4 \square$ & - & $-2.6(-10.7-5.4)$ & 0.518 \\
\hline Sumatra & 12.5 & 8.9 & $\bullet$ & $3.6(-0.8-8.0)$ & 0.114 \\
\hline Java \& Bali & 32 & 24.7 & $\rightarrow-$ & $7.3(2.3-12.3)$ & 0.04 \\
\hline \multicolumn{6}{|l|}{ Skilled birth attendance } \\
\hline Eastem Indonesia & 75.2 & 71.5 & 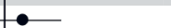 & $3.7(-4.1-11.5)$ & 0.352 \\
\hline Sulawesi & 92.1 & 86.2 & $\bullet$ & $5.9(0.3-11.5)$ & 0.038 \\
\hline Kalimantan & 96.2 & 93 & 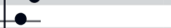 & $3.2(-0.9-7.4)$ & 0.127 \\
\hline Nusa Tenggara & 85.5 & 82.4 & 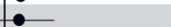 & $3.1(-5.7-10.0)$ & 0.372 \\
\hline Sumatra & 96.7 & 94 & $\bullet$ & $2.7(0.1-5.5)$ & 0.043 \\
\hline Java \& Bali & 96.2 & 94.7 & - & $1.5(-0.6-3.6)$ & 0.158 \\
\hline \multicolumn{6}{|l|}{ Facility-based delivery } \\
\hline Eastem Indonesia & 46.7 & 26.7 & $\bullet$ & $20.0(10.4-29.7)$ & $<0.0001$ \\
\hline Sulawesi & 77.0 & 60.4 & $\bullet$ & $16.6(7.4-25.7)$ & $<0.0001$ \\
\hline Kalimantan & 82.6 & 71.5 & $\longrightarrow$ & $11.1(2.9-19.3)$ & 0.008 \\
\hline Nusa Tenggara & 79.9 & 77.1 & $\bullet$ & $2.8(-5.1-10.7)$ & 0.487 \\
\hline Sumatra & 86.1 & 70.3 & $\bullet$ & $15.8(9.6-22.0)$ & $<0.0001$ \\
\hline Java \& Bali & 94.4 & 90.4 & $\bullet$ & $4.0(1.2-6.8)$ & 0.005 \\
\hline \multicolumn{6}{|l|}{ PNC } \\
\hline Eastem Indonesia & 67.8 & 53.7 & $\bullet$ & $14.1(4.0-24.2)$ & $<0.0001$ \\
\hline Sulawesi & 91.5 & 87.3 & - & $3.3(-1.1-9.7)$ & 0.125 \\
\hline Kalimantan & 89.8 & 81.2 & $\bullet$ & $8.5(-0.5-17.5)$ & 0.064 \\
\hline Nusa Tenggara & 84.4 & 83.7 & & $2.7(-3.8-9.2)$ & 0.419 \\
\hline Sumatra & 88.7 & 87.1 & - & $1.3(2.2-5.5)$ & 0.428 \\
\hline Java \& Bali & 93.8 & 91.0 & - & $2.8(0.3-6.0)$ & 0.036 \\
\hline \multicolumn{6}{|c|}{ PNC with skilled provider } \\
\hline Eastem Indonesia & 65.2 & 50.1 & $\bullet$ & $15.1(5.8-24.3)$ & 0.001 \\
\hline Sulawesi & 88.6 & 82.7 & $\bullet$ & $5.9(-0.3-12.1)$ & 0.060 \\
\hline Kalimantan & 89.4 & 79.4 & $\longrightarrow$ & $10.0(1.8-18.2)$ & 0.018 \\
\hline Nusa Tenggara & 83.5 & 82.6 & 6 & $0.91(-5.9-7.6)$ & 0.801 \\
\hline Sumatra & 87.9 & 86.6 & 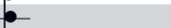 & $1.30(-2.8-5.3)$ & 0.532 \\
\hline \multirow[t]{2}{*}{ Java \& Bali } & 93.2 & 89.7 & $\rightarrow$ & $3.5(0.7-6.3)$ & 0.016 \\
\hline & \multicolumn{5}{|c|}{ 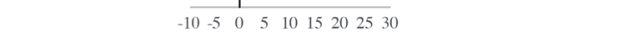 } \\
\hline
\end{tabular}

Figure 2. The average treatment effect on treated (ATT) of Jaminan Kesehatan Nasional (JKN) on maternal health services, by regional of residency. ANC - antenatal care, PNC - post-natal care. 
a) At least $4 \mathrm{ANC}$ visits

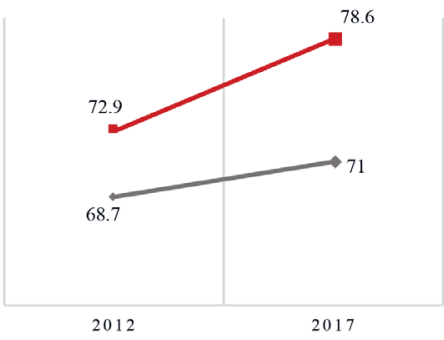

c) Skilled birth attendance

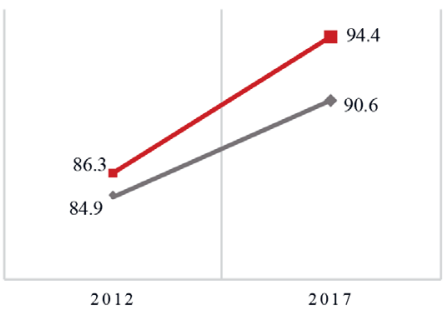

e) PNC

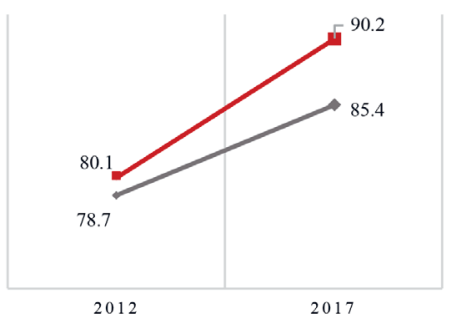

b) At least 4 ANC visits \& received clinical components of ANC

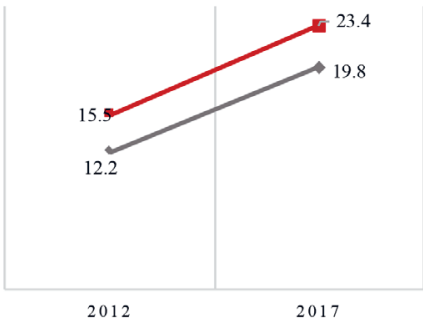

d) Facility-based delivery

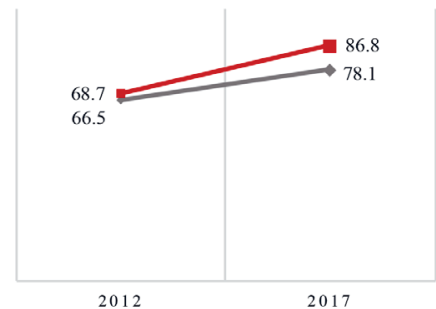

f) PNC with skilled provider

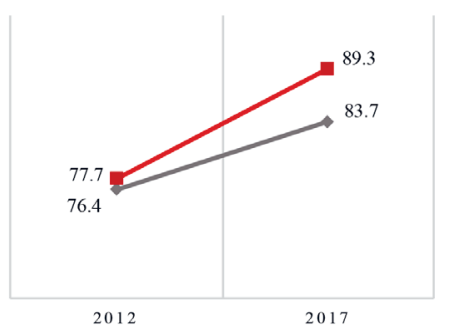

$\longrightarrow$ Social health insurance/JKN $\multimap$ Uninsured

Figure 3. Trend of maternal health services by health insurance enrolment, Indonesia 2012-2017. We only included women who had recent live birth in 2011-2012 (2012 IDHS) and 2016-2017 (2017 IDHS). Number of samples in $2012=4432$. Number of samples in $2017=5429$. Percentages and numbers are weighted.

\section{Unintended consequences of JKN}

We tested whether there were unintended negative impacts of JKN for uninsured women. According to Figure 3, the trend of maternal service utilisation increased for both the insured and uninsured from 2012 to 2017 . The trend increased for ANC4+ (68.7\% vs 71.0\%); ANC4+ with skilled providers (12.2\% vs $19.8 \%$ ); SBA ( $84.9 \%$ vs $90.6 \%$ ); facility-based delivery (66.5\% vs $78.1 \%)$; PNC (78.7\% vs $90.9 \%$ ); and PNC with skilled providers ( $76.4 \%$ vs $83.7 \%$ ) among the uninsured. Therefore, it appears that JKN was not associated with a reduction on utilisation among the uninsured.

\section{Sensitivity analysis and robustness check}

All matching algorithms show consistent results that implementation of JKN was associated with an improvement in access to maternal health services. NN with replacement had a higher ATT compared to others, but has a poorer quality of matching covariates (in Table S6 in the Online Supplementary Document). Using CEM reduced the sample size to 1657 observations or removed approximately $70 \%$ of observations compared to Kernel matching ( $\mathrm{N}=5705$ ). CEM results suggest a slightly lower effect of JKN compared to Kernel matching across six outcomes (in Table S8 in the Online Supplementary Document). However, no significant effect was observed in skilled birth attendance outcome. The results of sub-group analysis also demonstrate that the benefit of JKN appears more pronounced among poor groups. However, JKN is mostly not statistically significant in regional areas subgroup analysis, most likely due to the 
small sample sizes covariates (in Table S9-S10 in the Online Supplementary Document). Finally, the results of the MH test imply that the results are moderately robust and insensitive to hidden bias at $\Gamma=1.5$ in almost all outcome variables (in Table S11 in Online Supplementary Document). P-values obtained by multiple hypothesis testing indicates that association between JKN and maternal health service use is still significant at the 5\% significance level (in Table S12 in the Online Supplementary Document).

\section{DISCUSSION}

Our findings show that women insured by JKN have improved access to maternal health care services along the full continuum of care, compared with uninsured women. Our study also shows that these findings were more pronounced among women in the poorest quintile households and those residing in Eastern Indonesia, except for the quality of ANC visits. It is important to note that maternal health services coverage rates among higher wealth quintiles and in more developed regions are generally very high, and as such have less potential for increase as compared to lower coverage rates among the lower wealth quintiles and less developed regions. Thus, our results suggest that there is a greater potential for improvements when the coverage of maternal health services is low, for example, in lower-income groups and less developed regions. However, the findings indicate that JKN is far from closing the gap in access between the poor and non-poor: inequalities still persist in the coverage of maternal health services across socioeconomic groups and geographical areas of Indonesia. These inequalities imply an inequitable distribution of the subsidy and maternal health services provided within JKN. While a full benefit incidence analysis is beyond the scope of this paper, clearly JKN funding follows utilisation, and is concentrated where utilisation is highest in absolute terms. More remains to be done in supporting improved access to services in marginalised population groups.

Our findings are consistent with previous studies from Indonesia and other LMICs [20,22,23,30,40-42]. Most studies have found health insurance to be significantly associated with an increased use of health care services. Despite these findings, our study is consistent with others in finding that JKN has not closed the gap of access to services within regions, in particular in Eastern Indonesia, where the availability of human resources for health and facilities is still much lower compared to other regions $[16,20,43]$. In India, a conditional cash transfer program was found to have a greater effect on maternal health service use in worse-off states with low coverage of maternal health services, compared to better-off states $[41,44]$.

Despite this study's promising findings, our findings suggested that the impact of JKN on quality of ANC was more pronounced among the higher socio-economic groups. Poor supply-side readiness and inadequate quality of care remain important challenges in Indonesia [9,12,45-47]. The referral system is still lacking, resulting in delays in service provision. Necessary supplies and equipment, such as blood transfusion, may not always be available [47]. These challenges are particularly evident in East Kalimantan, a province with the highest rates of facility-based delivery and SBA in Kalimantan but persistently high MMR [46]. The 2016 Indonesia Quantitative Service Delivery Survey revealed that the ability of health providers to deliver ANC, identify risk of complications, and manage complications according to guidelines is still weak [9]. While this study used limited measures of quality of care, it is clear that expanding coverage of health insurance should be done simultaneously with improving supply-side readiness, and progress towards UHC should also be measured through the lens of service quality [48].

WHO Strategies toward Ending Preventable Maternal Mortality seeks to "ensure universal health coverage for comprehensive sexual, reproductive, maternal and newborn health" [2]. Based on current trends, Indonesia failed to achieve UHC by 2019 and may only achieve this target by 2034 [13,19]. One of the obstacles to achieving UHC is reaching the 'missing middle population' or those who work in the informal sector with lower-middle income $[12,13,43,49]$. In 2016 , only $7 \%$ of this population was covered by JKN [49]. Since they must pay insurance premiums themselves, their willingness-to-pay becomes an important underlying factor that determines their enrolment. The poor availability and accessibility to health care services, as well as lack of understanding on the significance of health insurance are the main reasons that could impede their participation in the JKN $[12,50]$. Efforts should be made to reduce the disparities in the availability of health services in less-developed regions and raise public awareness about the importance of health insurance, in addition to the use of sanctions for individuals and employers [12,51].

Another major problem is a potential mistargeting of the poor and non-poor [12,49]. Despite eligibility rules for full or partially subsidized premiums for the very poor and near-poor, around $40.8 \%$ of the very poor households in our sample were not covered by JKN in 2017. A report published by World Bank 
produced a similar result: around half of very poor households, which should be categorized as subsidized participants, were uninsured by JKN in 2016 [49]. BPJS-K and Ministry of Social Affairs should collaborate with local government to validate the lists of poor and near-poor households and eliminate mistargeting subsidised beneficiaries.

This study has several important limitations. First, enrolment status in JKN was asked at the time of the interview, not at the time of pregnancy and delivery. We assumed that women had the same enrolment status at the time of interview and during their previous pregnancy. We attempted to address this timing issue by only including women who had had a recent live birth between 2016-2017, a year preceding the survey, as others have done $[30,40,42]$. Second, although PSM can reduce the selection bias of JKN enrolment, the analysis was cross-sectional and can only demonstrate the association between the variables, not causality. It is plausible that those who have opportunities to use maternal services have more motivation to enrol in JKN than those who do not, for example because they live distant from available services. Third, the analysis may still be subject to the problem of unobservable characteristics. For example, we have not included controls for religion or ethnicity, which have been found to be associated with utilisation of maternal health services $[16,30,42]$, but was not available in the data set. We attempted to minimise and test for the potential for bias through sensitivity analyses. Different matching techniques and tests for unobserved confounding indicate these results are robust and insensitive to bias. Fourth, sample sizes for some of the regional sub-group analyses were small, resulting in insignificant results with very wide confidence intervals. Fifth, we only conducted pre- and post-analysis using serial cross-sectional data from 2012 and 2017, which may not reflect the current pattern. Our trend analysis may also be limited by issues of selection bias and unobservable confounding as the uninsured population pre-JKN may not be comparable with the uninsured post-JKN. Further analyses are needed to explore this further with longitudinal data if possible. Despite these limitations, our study offers compelling evidence on the positive association of health insurance on utilisation of care at a national level, and sub-nationally by income group and regional area.

\section{CONCLUSIONS}

This is the first study assessing the effect of JKN on access to maternal health services across the continuum of care, using the most recent nationally representative data. Evidence from this study reveals that government efforts to eliminate financial barriers and provide equitable access through national health insurance can lead to improved access to maternal health services, especially for disadvantaged groups. However, there remain significant socioeconomic and regional inequality in access to maternal health services in Indonesia. Continued health system reforms in Indonesia must place greater emphasis on providing improved access to those disadvantaged groups.

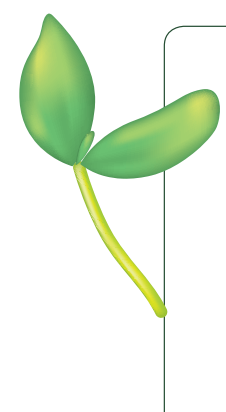

Acknowledgements: The authors acknowledge the DHS program that collects this data and makes them publicly available for research purposes.

Availability of data and material: The report and dataset are publicly available by registering the abstract and analysis plan at https://dhsprogram.com/data/dataset/Indonesia_Standard-DHS_2017.cfm?flag=0.

Ethics approval: This research uses a secondary data of 2017 IDHS survey. Procedures and questionnaires for the 2017 IDHS survey had been reviewed and approved by the ICF International Institutional Review Board (IRB), and the survey protocols have been reviewed by the ICF IRB, the Indonesian Ministry of Health, and the BKKBN for the protection of human subjects.

Funding: NC is supported by a University of Melbourne McKenzie Postdoctoral Fellowship.

Authorship contributions: KA and NC conceived and designed the study. KA and JTL conducted the data analysis and prepared the tables and figures with input from NC and BMcP. BMcP, SAW, CM provided critical input in revising the manuscript. All authors contributed to interpreting the results and writing of the manuscript.

Competing interests: The authors completed the ICMJE Unified Competing Interest form (available upon request from the corresponding author) and declare that they have no competing interests.

Additional material

Online Supplementary Document 
1 World Health Organization. Maternal mortality: key facts 2018. Available: https://www.who.int/news-room/fact-sheets/ detail/maternal-mortality. Accessed: 30 April 2019.

2 World Health Organization. Strategies toward ending preventable maternal mortality (EPMM). Geneva: WHO, 2015.

3 GBD 2015 Maternal Mortality Collaborators. Global, regional, and national levels of maternal mortality, 1990-2015: a systematic analysis for the Global Burden of Disease Study 2015. Lancet. 2016;388:1775-812. Medline:27733286 doi:10.1016/S0140-6736(16)31470-2

4 The Association of Southeast Asian Nations (ASEAN) Secretariat. ASEAN Statistical Report on Millennium Development Goals 2017. Jakarta: 2017.

5 Statistics Indonesia (BPS). 2015 Intercensal Population Survey. Jakarta: BPS, 2015.

6 Statistics Indonesia. Maternal mortality ratio by island. 2015 Intercensal Popul Surv. 2018. Available: https://www.bps. go.id/dynamictable/2018/06/05/1439/angka-kematian-ibu-menurut-pulau-per-100-000-kelahiran-hidup-2015.html. Accessed: 10 March 2019.

7 Knaul FM, Langer A, Atun R, Rodin D, Frenk J, Bonita R. Rethinking maternal health. Lancet Glob Health. 2016;4:e2278. Medline:26953968 doi:10.1016/S2214-109X(16)00044-9

8 Miller S, Belizán JM. The true cost of maternal death: Individual tragedy impacts family, community and nations. Reprod Health. 2015;12:56. Medline:26081494 doi:10.1186/s12978-015-0046-3

9 Yap WA, Pembudi ES, Marzoeki P, Cain JS, Tandon A. Revealing the missing link: Private sector supply-side readiness for primary maternal health services in Indonesia. Jakarta: World Bank, 2017.

10 World Health Organization. State of inequality: reproductive, maternal, newborn, and child health. Geneva: WHO; 2015.

11 Belton S, Myers B, Ngana FR. Maternal deaths in eastern Indonesia: 20 years and still walking: an ethnographic study. BMC Pregnancy Childbirth. 2014;14:39. Medline:24447873 doi:10.1186/1471-2393-14-39

12 Agustina R, Dartanto T, Sitompul R, Susiloretni KA, Achadi EL, et al. Universal health coverage in Indonesia: concept, progress, and challenges. Lancet. 2019;393:75-102. Medline:30579611 doi:10.1016/S0140-6736(18)31647-7

13 Wiseman V, Thabrany H, Asante A, Haemmerli M, Kosen S, Gilson L, et al. An evaluation of health systems equity in Indonesia: study protocol. Int J Equity Health. 2018;17:138. Medline:30208921 doi:10.1186/s12939-018-0822-0

14 National Research Council. Reducing Maternal and Neonatal Mortality in Indonesia: Saving Lives, Saving the Future. Washington, DC: The National Academies Press; 2013

15 World Health Organization and International Bank for Reconstruction and Development / The World Bank. Tracking universal health coverage: 2017 global monitoring report. 2017.

16 Nababan HY, Hasan M, Marthias T, Dhital R, Rahman A, Anwar I. Trends and inequities in use of maternal health care services in Indonesia, 1986-2012. Int J Womens Health. 2017;10:11-24. Medline:29343991 doi:10.2147/IJWH.S144828

17 Mboi N, Murty Surbakti I, Trihandini I, Elyazar I, Houston Smith K, Bahjuri Ali P, et al. On the road to universal health care in Indonesia, 1990-2016: a systematic analysis for the Global Burden of Disease Study 2016. Lancet. 2018;392:58191. Medline:29961639 doi:10.1016/S0140-6736(18)30595-6

18 Social Security Agency for Health. Total participants of JKN 2019. Available: https://bpjs-kesehatan.go.id/bpjs/. Accessed: 27 December 27 2019).

19 Defisit BPJS Kesehatan Belum Akan Berakhir. Suara Pembaruan 2018:3.

20 Teplitskaya L, Dutta A. Has Indonesia's National Health Insurance Scheme Improved Access to Maternal and Newborn Health Services? Washington, DC: Palladium, Health Policy Plus, 2018.

21 Global Burden of Disease Health Financing Collaborator Network. Past, present, and future of global health financing: a review of development assistance, government, out-of-pocket, and other private spending on health for 195 countries, 1995-2050. Lancet. 2019;393:2233-60. Medline:31030984 doi:10.1016/S0140-6736(19)30841-4

22 Brooks MI, Thabrany H, Fox MP, Wirtz VJ, Feeley FG, Sabin LL. Health facility and skilled birth deliveries among poor women with Jamkesmas health insurance in Indonesia: a mixed-methods study. BMC Health Serv Res. 2017;17:105. Medline:28148258 doi:10.1186/s12913-017-2028-3

23 Wang W, Temsah G, Mallick L. The impact of health insurance on maternal health care utilization: evidence from Ghana, Indonesia and Rwanda. Health Policy Plan. 2017;32:366-75. Medline:28365754

24 Erlangga D, Ali S, Bloor K. The impact of public health insurance on healthcare utilisation in Indonesia: evidence from panel data. Int J Public Health. 2019;64:603-13. Medline:30737522 doi:10.1007/s00038-019-01215-2

25 von Elm E, Altman DG, Egger M, Pocock SJ, Gøtzsche PC, Vandenbroucke JP, et al. The Strengthening the Reporting of Observational Studies in Epidemiology (STROBE) statement: guidelines for reporting observational studies. Lancet. 2007;370:1453-7. Medline:18064739 doi:10.1016/S0140-6736(07)61602-X

26 National Population and Family Planning Board (BKKBN), Statistics Indonesia (BPS), Ministry of Health. (Kemenkes), and ICF. Indonesia demographic and health survey 2017. Jakarta: BKKBN, BPS, Kemenkes, and ICF, 2018.

27 Statistics Indonesia (BPS), National Population and Family Planning Board (BKKBN), Ministry of Health. (Kemenkes), and ICF International. Indonesia demographic and health survey 2012. Jakarta: BPS, BKKBN, Kemenkes, and ICF International, 2013

28 Minister of Health of the Republic of Indonesia. Ministry of Health Decree no 97/2014 on Pre-natal, Pregnancy, Postnatal, Sexual and Reproductive Health Services. 2014.

29 World Health Organization. Skilled birth attendants 2014. Available: https://www.who.int/reproductivehealth/topics/ mdgs/skilled_birth_attendant/en/. Accessed: 14 May 142019.

30 Bonfrer I, Breebaart L, Van de Poel E. The effects of Ghana's national health insurance scheme on maternal and infant health care utilization. PLoS One. 2016;11:e0165623. Medline:27835639 doi:10.1371/journal.pone.0165623 
31 Stuart EA, Lee BK, Leacy FP. Prognostic score-based balance measures can be a useful diagnostic for propensity score methods in comparative effectiveness research. J Clin Epidemiol. 2013;66:S84-S90. Medline:23849158 doi:10.1016/j. jclinepi.2013.01.013

32 Ali MS, Groenwold RHH, Klungel OH. Best (but oft-forgotten) practices: Propensity score methods in clinical nutrition research. Am J Clin Nutr. 2016;104:247-58. Medline:27413128 doi:10.3945/ajcn.115.125914

33 Rubin DB. Using Propensity Scores to Help Design Observational Studies: Application to the Tobacco Litigation. Health Serv Outcomes Res Methodol. 2001;2:169-88. doi:10.1023/A:1020363010465

34 Ravit M, Ravalihasy A, Audibert M, Ridde V, Bonnet E, Raffalli B, et al. The impact of the obstetrical risk insurance scheme in Mauritania on maternal healthcare utilization: a propensity score matching analysis. Health Policy Plan. 2020;35:38898. Medline:32003810 doi:10.1093/heapol/czz150

35 Jann B. KMATCH: Stata module module for multivariate-distance and propensity-score matching, including entropy balancing, inverse probability weighting, (coarsened) exact matching, and regression adjustment 2017. Available: https:// ideas.repec.org/c/boc/bocode/s458346.html. Accessed: 10 February 2019.

36 Blackwell M, Iacus S, King G, Porro G. Coarsened Exact Matching in Stata. 2010.

37 Becker SO, Caliendo M. Sensitivity analysis for average treatment effects. StataJ. 2007;7:71-83. doi:10.1177/1536867X0700700104

38 Streiner DL. Best (but oft-forgotten) practices: the multiple problems of multiplicity-whether and how to correct for many statistical tests. Am J Clin Nutr. 2015;102:721-8. Medline:26245806 doi:10.3945/ajcn.115.113548

39 Newson R. Multiple-test procedures and smile plots. Stata J. 2003;3:109-32. doi:10.1177/1536867X0300300202

40 Mensah J, Oppong JR, Schmidt CM. Ghana's national health insurance scheme in the context of the health MDGs: an empirical evaluation using propensity score matching. Health Econ. 2010;19:95-106. Medline:20730999 doi:10.1002/hec.1633

41 Lim SS, Dandona L, Hoisington JA, James SL, Hogan MC, Gakidou E. India's Janani Suraksha Yojana, a conditional cash transfer programme to increase births in health facilities: an impact evaluation. Lancet. 2010;375:2009-23. Medline:20569841 doi:10.1016/S0140-6736(10)60744-1

42 Gouda HN, Hodge A, Bermejo R, Zeck W, Jimenez-Soto E. The impact of healthcare insurance on the utilisation of facility-based delivery for childbirth in the Philippines. PLoS One. 2016;11:e0167268. Medline:27911935 doi:10.1371/ journal.pone.0167268

43 Hartwig R, Sparrow R, Budiyati S, Yumna A, Warda N, Suryahadi A, et al. Effects of decentralized health-care financing on maternal care in Indonesia. Econ Dev Cult Change. 2019;67:659-86. doi:10.1086/698312

44 Carvalho N, Rokicki S. The impact of India's Janani Suraksha Yojana Conditional Cash Transfer Programme: A replication study. J Dev Stud. 2019;55:989-1006. doi:10.1080/00220388.2018.1506578

45 Yogesh R, Jessica G, Iva D, Sayaka K, Martha C, Kebba J, et al. Re-envisioning maternal and newborn health in Indonesia: how the private sector and civil society can ignite change. Washington, DC: Palladium, Health Policy Plus, 2016.

46 Mahmood MA, Mufidah I, Scroggs S, Siddiqui AR, Raheel H, Wibdarminto K, et al. Root-cause analysis of persistently high maternal mortality in a rural district of Indonesia: Role of clinical care quality and health services organizational factors. Biomed Res Int. 2018;2018. Medline:29682538 doi:10.1155/2018/3673265

47 Rosales A, Sulistyo S, Miko O, Hairani LK, Ilyana M, Thomas J, et al. Recognition of and care-seeking for maternal and newborn complications in Jayawijaya district, Papua province, Indonesia: a qualitative study. J Health Popul Nutr. 2017;36:44. Medline:29297380 doi:10.1186/s41043-017-0122-0

48 Kruk ME, Gage AD, Arsenault C, Jordan K, Leslie HH, Roder-DeWan S, et al. High-quality health systems in the Sustainable Development Goals era: time for a revolution. Lancet Glob Health. 2018;6:e1196-252. Medline:30196093 doi:10.1016/S2214-109X(18)30386-3

49 Tandon A, Pambudi E, Harimurti P, Masaki E, et al. Indonesia Health Financing System Assessment Spend More, Right and Better. Jakarta: World Bank; 2016.

50 Dartanto T, Rezki JF, Pramono W, Siregar CH, Bintara U, Bintara H. Participation of informal sector workers in Indonesia's national health insurance system. J Southeast Asian Econ. 2016;33:317-42. doi:10.1355/ae33-3c

51 Yustina EW, Budisarwo J, Eddy L. The implementation of the national health insurance based on gotong-royong principle as the efforts of enhancing the welfare. Int J Soc Sci Humanit. 2017;7:299-303. 